\title{
Review: at least one third of people report persistent memory loss after electroconvulsive therapy
}

Rose $D$, Wykes $T$, Leese $M$, et al. Patients' perspectives on electroconvulsive therapy: systematic review. BMJ 2003;326:1363.

What are patients' views on the treatment benefits of electroconvulsive therapy and to what extent is persistent loss of memory an adverse effect of this treatment?

METHODS

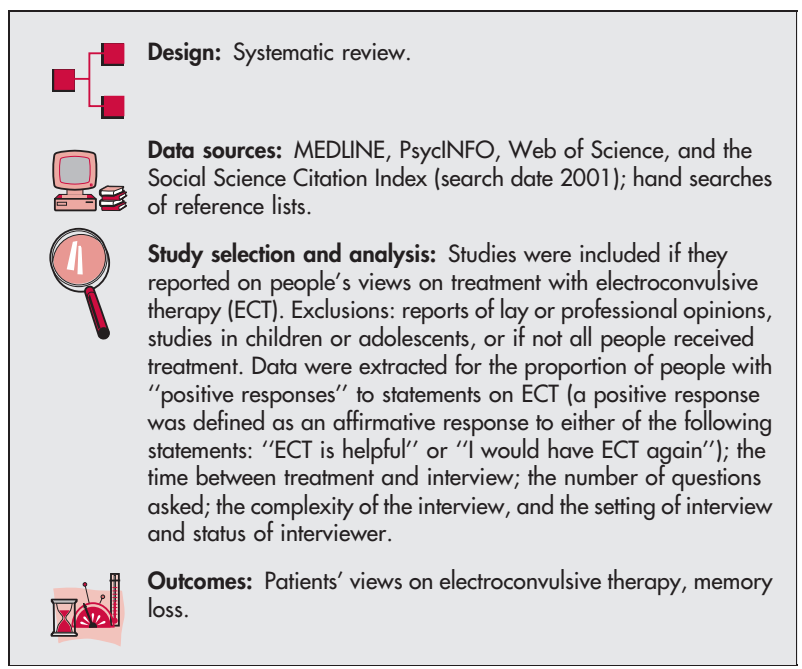

\section{MAIN RESULTS}

Thirty five studies met inclusion criteria. Perceived benefit: there was substantial heterogeneity among studies (see Notes). The studies reported that between $20 \%$ and $90 \%$ of people found ECT helpful. However, the reported efficacy was related to methodological features of the included studies. People were more likely to report positive views on ECT if they were interviewed soon after treatment. Conversely, people who were not interviewed by their treating doctor or who were interviewed at home were less likely to report positive views. Safety: among 7 studies that reported on memory loss, the rate of persistent or permanent memory loss after ECT ranged from $29 \%$ to $55 \%$.

\section{CONCLUSIONS}

Studies examining perceived benefits of ECT among patients may be biased by their methods. However, there appears to be consistent evidence that memory loss is common following ECT.
For correspondence: Diana Rose, Department of Psychology, Institute of Psychiatry, De Crespigny Park, London, SE5 8AF, UK; d.rose@iop.kcl.ac.uk Source of funding: a grant from the Department of Health, England.

\section{NOTES}

The systematic review did not exclude studies based on their design or quality of their methods. It is not surprising, therefore, to find heterogeneity of results. However the study goes further in examining sources of heterogeneity, and importantly it demonstrates consistent evidence of harm (memory loss).

Commentary

M ore than any other treatment modality in medicine, ECT remains controversial and misunderstood. Thus, understanding patients' subjective experiences of this procedure is of great importance. The "official" stance from the clinician's point of view is that there is no evidence that ECT produces structural brain damage. ${ }^{1}$ While it has long been acknowledged that patients do subjectively experience memory loss following ECT, the official line from the clinician's point of view has been that this is very difficult to quantify objectively, ${ }^{2}$ and even modern texts continue to pay lip service to the impact of memory loss on patients' lives. ${ }^{3}$

A critical look at the literature on memory loss following ECT shows it to be rather confusing and contradictory, and very much dependent on the perspective of the researcher. ${ }^{4}$ Quantitative studies are, by their nature, superficial and do not come close to approaching the complexity of the nature of the experience of the patient. Qualitative studies, by their nature, are small, and not able to be generalised. Rose and colleagues in their attempt at a systematic review, have found that results are difficult to compare, are frequently dependent on factors other than the ECT itself, and have confirmed that this controversial area is difficult to study. They correctly conclude that, given the lack of rigour of the available evidence, clinicians cannot assume that over $80 \%$ of patients are satisfied with ECT, or are not subjectively troubled by persistent memory loss.

While there is no doubting the effectiveness of ECT, patients' perspectives do need to be explored in different ways. While qualitative studies go some way to doing this, we are at a point in our knowledge where this systematic attempt by Rose and colleagues can be used as a spur to design combined qualitative and quantitative studies of greater validity.

Leslie F Koopowitz MBBCh FFPsych(SA) FRANZCP Senior Consultant Psychiatrist, Royal Adelaide Hospital, Glenside Campus, and Clinical Senior, Lecturer in Psychiatry, University of Adelaide, Adelaide, Australia

1 Devenand DP, Dwork AJ, Hutchinson ER, Bolwig TG, Sackeim HA. Does ECT alter brain structure? Am J Psychiatry 1994:151:957-70.

2 Fink M. Convulsive Therapy: theory and practice. New York: Raven Press, 1979.

3 Tiller JWG, Lyndon RW. Electroconvulsive therapy: an Australasian guide. Victoria: Australian Postgraduate Medicine, 2003.

4 Koopowitz LF, Chur-Hansen A, Reid S, et al. The subjective experience of patients who received electroconvulsive therapy. Aust N Z J Psychiatry 2003;37:49-54. 